\title{
LETRAMENTOS E TECNOLOGIAS DIGITAIS NA EDUCAÇÃO PROFISSIONAL E TECNOLÓGICA
}

\author{
Angela Bustos Kleiman, Ivoneide Bezerra de Araújo Santos Marques \\ Universidade Estadual de Campinas \\ DOI: $10.15628 /$ rbept.2018.7514
}

Artigo submetido em jun/2018 e aceito em out/2018

\begin{abstract}
RESUMO
Neste trabalho, nosso objetivo é discutir aspectos que envolvem o trabalho com as tecnologias digitais no processo educacional de alunos vinculados ao Ensino Médio Integrado no contexto específico da Educação de Jovens e adultos no PROEJA. Refletimos sobre ambiguidades e omissões nos documentos regulatórios do Ensino Médio que caracterizam o tratamento da Educação Profissional e Tecnológica nas diversas políticas públicas da federação que fornecem parâmetros importantes à discussão desenvolvida. Propomos alguns princípios que, uma vez observados, poderiam nortear o trabalho com as práticas de letramento desenvolvidas na EPT, para começar a atender às expectativas, necessidades de participação social e política dos estudantes. Concluímos que, enquanto os trabalhadores em formação ou outros possíveis alunos egressos da EPT continuarem chegando ao mundo do trabalho sem que a escola tenha dado respostas mais concretas às suas demandas de letramentos, esta continuará sendo reprodutora de desigualdades sociais, pois não garante aos educandos o direito aos letramentos como condição de acesso e permanência no mundo do trabalho e de inclusão social.
\end{abstract}

Palavras-Chave: Letramento. BNCC. Tecnologias Digitais. Educação Profissional. PROEJA.

\section{DIGITAL LETTERS AND TECHNOLOGIES IN PROFESSIONAL AND TECHNOLOGICAL EDUCATION}

\begin{abstract}
In this paper, we aim to discuss educational aspects regarding the teaching of high school level digital information technologies in Adult and Youth Professional and Technical Education Programs in Brazil (PROEJA). We point out ambiguities and omissions in recent federal documents that will regulate professional and technical streams in high school education. We propose a set 0 principles that could be used as guidelines for digital literacy practices developed in Professional and Technical Education na EPT(EPT) to begin to attend expectations, and social and political participation needs on the students' part. We conclude that as long as student workers and other EPT highschool graduates continue to arrive at the work market without their literacy needs having been satisfied in concrete ways at school, social inequalities will continue to be reproduced, for as long as school fails to guarantee its students the right to digital literacies as a condition for work access and job maintenance and for social inclusion.
\end{abstract}

Keywords: Literacis. Digital Technologies. Professional Education. PROEJA. 
Para que saber informática? A empresa pega a gente e manda carregar peso para o almoxarifado. Para que se preparar para usar o computador e depois quererem você para descarregar caminhão de mercadorias?

Paulo - Aluno do Curso de Eletrotécnica - PROEJA

\section{CONSIDERAÇÕES INICIAIS}

A Educação Profissional e Tecnológica Brasileira (EPT), uma das modalidades de ensino previstas na Lei de Diretrizes e Bases da Educação Nacional - LDB, Lei no 9.394/96 (BRASIL, 1996), oferece formação técnica de nível médio com a oferta de cursos técnicos integrados, articulando formação geral e formação profissional, segundo as bases teórico-metodológicas, os princípios e os fundamentos do currículo integrado.

De forma sistematizada, desde 2008, essa modalidade educacional está em fase de expansão, com a ampliação da rede de escolas, da oferta de vagas e das modalidades de ensino oferecidas. A primeira fase desse crescimento aconteceu no período de 2008 - 2010; a segunda de 2011 a 2012; a terceira de 2013 a 2014. O projeto de expansão e de reestruturação da Rede Federal de Educação Profissional e Tecnológica foi pensado para ampliar a oferta em escolas federais nos estados, municípios e nas periferias de grandes cidades, visando, primordialmente, à democratização do acesso da população a uma educação pública de qualidade, numa perspectiva de diminuição das desigualdades regionais e de um desenvolvimento social sustentável.

Assim, com a publicação da Lei 11.892, de 29 de dezembro de 2008, surgem, no cenário educacional brasileiro os Institutos Federais, antigos Centros de Educação Tecnológica (CEFET). Os Institutos assumem, nesse novo cenário, não só uma nova institucionalidade, mas, sobretudo, novos desafios relacionados à EPT e, consequentemente, à formação da classe trabalhadora do país, seguindo princípios do Plano Nacional de Educação (PNE). Atualmente, esse processo de ampliação ainda não está concluído e, embora aconteça de forma menos sistemática do que nas etapas anteriores, ainda contribui para aumentar consideravelmente a oferta de educação profissional em todo o país.

Contudo, para além da construção de novas escolas técnicas e do consequente aumento da oferta de vagas tanto na modalidade presencial quanto na modalidade à distância, por meio do Programa Escola Técnica Aberta do Brasil (E-TEC), à educação profissional se impõem desafios urgentes, por ter como atividade fim a formação da classe trabalhadora. Um dos mais relevantes critérios para o planejamento e a oferta dessa modalidade de ensino é que se leve em consideração 0 atendimento às demandas dos cidadãos, do mercado de trabalho e da sociedade. 
Em um país como o nosso, onde pesquisas informam haver 13,1 milhões de desempregados no primeiro trimestre de 20181, a formação técnica e profissional deve contribuir para a qualificação ou requalificação da classe trabalhadora e para a redução de desigualdades sociais, gerando oportunidades de acesso à cidadania. Isso exige da EPT práticas pedagógicas inovadoras e novas ferramentas para o ensino e para a aprendizagem dos estudantes, preparando-os para sua inserção, ou manutenção, no mercado de trabalho, por meio de uma formação profissional que atenda às demandas da sociedade tecnológica. Nesse sentido, um dos maiores desafios dessa modalidade educativa é o planejamento de um sistema disciplinar que não se restrinja a fatores econômicos nem se subjugue às demandas e necessidades do mercado de trabalho.

Incorporada como "itinerário formativo" no âmbito da Base Nacional Curricular Comum (BNCC) do Ensino Médio (que tramita atualmente no Conselho Nacional de Educação, CNE), a Formação Técnica Profissional não parece manter uma relação coesa com nenhuma das áreas de conhecimento descritas nesse documento. Para cada área geral do conhecimento foram estabelecidas competências específicas, a serem desenvolvidas duplamente, "tanto no âmbito da BNCC como dos itinerários formativos das diferentes áreas" (p. 33). Significa isso, então, que o currículo do itinerário formativo da Formação Técnica Profissional não é construído em relação às áreas no âmbito da BNCC, mas independentemente delas?2 Isso poderia se configurar como uma fragmentação na organização dos conteúdos, quando a própria base orienta o diálogo dos diferentes componentes curriculares a partir da interdisciplinaridade.

Nota-se, já na Base, uma invisibilização do segmento técnico profissional que não augura nada de bom para os educandos que viajam nesse itinerário, utilizando veículos e instrumentos de terceira classe, que já nascem pobres na sua concepção de necessidades do alunado que "opta" por esse segmento, a maioria também de origem pobre. A finalidade da Educação Profissional e Tecnológica é garantir ao aluno o direito à aquisição de competências profissionais que o tornem apto para a inserção em setores profissionais nos quais haja utilização de tecnologias, mas a viabilidade desse objetivo é nula sem oportunidades de aprofundamento acadêmico nas diversas áreas que compõem o currículo do Ensino Médio.

Questões como essas norteiam este trabalho, que compreende a Educação Profissional e Tecnológica como uma modalidade de educação integrada ao trabalho, à ciência e à tecnologia, como propõem os documentos que a regulamentam, mas também às artes, à vida física, à atuação política. $O$ nosso objetivo, neste trabalho, é discutir aspectos que envolvem o trabalho com as tecnologias digitais no processo educacional de

\footnotetext{
1 Disponível em: https://www1.folha.uol.com.br/. Acesso em: 13 de jun de 2018.

2 Alternativa fortemente sugerida no Quadro das Competências Gerais para a Educação Básica - BNCC/ Ensino Médio, p. 468. 
alunos vinculados ao Ensino Médio Integrado no contexto específico da Educação de Jovens e adultos no PROEJA ${ }^{3}$. Ambiguidades e omissões nos documentos regulatórios do Ensino Médio que caracterizam o tratamento da Educação técnica e profissional nas diversas políticas públicas da federação fornecerão parâmetros importantes à discussão. Dada à relevância dessas questões e a importância de refletir sobre elas no atual contexto brasileiro, consideramos que educação, ciência e tecnologia necessitam ser submetidas à crítica permanentemente.

O texto está organizado em quatro partes. Seguindo estas considerações iniciais,, discutimos a Educação Profissional e Tecnológica, no atual cenário da Reforma do Ensino Médio e da iminente publicação da versão final da Base Nacional Comum Curricular para o Ensino Médio (BNCC), focalizando problemas e limitações dessas políticas públicas, muitos deles já apontados na literatura pertinente, em relação ao curso técnico que nos interessa, o PROEJA, ofertado pela Rede Federal de Educação Profissional Científica e Tecnológica. Na seção seguinte, discutimos as recomendações da BNCC sobre tecnologias digitais na Educação Profissional e Tecnológica, para, em seguida, examinarmos as reais possibilidades de utilização de tecnologias de forma crítica, significativa, reflexiva e ética no segmento educacional em foco, o PROEJA. Na última parte deste artigo, apresentamos considerações finais.

\section{A EDUCAÇÃO PROFISSIONAL E TECNOLÓGICA NO ENSINO MÉDIO}

o PROEJA é a oportunidade de mudar minha vida e melhorar nisso pra não perder o trabalho [...] acho importante aprender a escrever o relatório de estágio, o currículo, fazer e-mail [...] importante também pensar sobre o que fazemos no curso, no projeto discute muita coisa [...] ficamos mais conscientes, né? Por um lado isso é bom mas por outro a gente não se conforma com certas coisas [...].

No atual cenário da educação básica brasileira, os documentos reguladores do Ensino Médio (Reforma do Ensino Médio (REM) e Base Nacional Curricular Comum (BNCC) do Ensino Médio), têm sido alvo de críticas por diversas entidades da comunidade acadêmica comprometida com

\footnotetext{
${ }^{3}$ Programa Nacional de Integração da Educação Profissional com a Educação Básica na Modalidade de Educação de Jovens e Adultos. Como uma ação afirmativa no campo das políticas públicas, o PROEJA foi pensado para ser desenvolvido na rede pública federal e estadual de ensino e instituído por meio do Decreto número 5.478 de 24/06/2005, a fim de contribuir com o alcance das metas estabelecidas na primeira proposta do Plano Nacional de Educação (PNE - 2011-2020).
} 
questões educacionais, antes mesmo de eles entrarem efetivamente em vigência. Algumas entidades contrárias à BNCC subscreveram um "Manifesto de repúdio" 4 a essa base curricular pelo seu potencial como mecanismo de controle e de cerceamento de autonomia passível de ser exercido em relação às políticas e programas de formação de professores do Ministério da educação (MEC).

Além desse movimento de resistência dessas entidades, outros gestos desfavoráveis aos dois documentos se avolumam em todo o país, tais como a "Carta aberta em defesa da Educação Profissional Técnica integrada ao ensino médio", publicada recentemente por profissionais do Instituto Federal de Alagoas (IFAL). Essas manifestações foram precedidas pela "Carta de Natal", produzida durante o IV Colóquio Nacional / I Colóquio Internacional intitulado A Produção do Conhecimento em Educação Profissional: a reforma do ensino médio e suas implicações para a educação profissional ${ }^{5}$, por um coletivo acadêmico integrado por pesquisadores, educadores e estudantes de ensino médio, de graduação e de pós-graduação provenientes de todas as regiões brasileiras (inclusive alguns do exterior).

Grande parte das críticas aos documentos oficiais incide na sua fragmentação. A Reforma do Ensino Médio, referendada pela Lei 13.415/2017, limita as áreas do currículo a Matemática e Língua Portuguesa, em detrimento de outros componentes curriculares também importantes para a formação integral dos alunos, tais como, Filosofia, Sociologia, História, Artes, Educação Física etc., sob o argumento de que em torno dessas duas maiores, outras áreas de conhecimento poderão se agregar, estabelecendo, assim, o diálogo entre conhecimentos de diferentes componentes curriculares de forma interdisciplinar.

É difícil escapar a conclusão de que a escolha (e consequente hierarquização) das duas áreas de conhecimento que estão no cerne das avaliações de larga escala (Programa Internacional de Avaliação de Estudantes/PISA em nível internacional e Exame Nacional do Ensino Médio/ENEM em nível nacional) visa melhorar os níveis de desempenho dos alunos do Ensino Médio nessas duas áreas, apenas preparando-os para a realização dessas provas. Em outras palavras, a proposta revela objetivos instrumentalistas para cuja consecução não interessa a formação global do

\footnotetext{
${ }^{4}$ Documento subscrito por entidades como Associação Nacional de Pós-Graduação e Pesquisa em Educação (ANPEd); Associação Nacional pela Formação dos Profissionais da Educação (ANFOPE); Confederação Nacional dos Trabalhadores em Educação (CNTE); Fórum Nacional de Diretores de Faculdades, Centros de Educação ou Equivalentes das Universidades Públicas Brasileiras (FORUMDIR); Associação Nacional de Política e Administração da Educação (ANPAE); Associação Brasileira de Currículo (ABdC); Centro de Estudos Educação e Sociedade (CEDES); Associação Nacional de Pesquisa em Financiamento da Educação (FINEDUCA); Campanha Nacional pelo Direito à Educação; Ação Educativa e Movimento Nacional em Defesa do Ensino Médio (MNDEM).

${ }^{5}$ Evento realizado no Campus Natal Central do Instituto Federal de Educação, Ciência e Tecnologia do Rio Grande do Norte, no período de 24 a 27/07/2017. 
aluno. Que, no entanto, deveria interessar à nação. A final de contas, "está em jogo a recriação da escola que, embora não possa por si só resolver as desigualdades sociais, pode ampliar as condições de inclusão social, ao possibilitar o acesso à ciência, à tecnologia, à cultura e ao trabalho (BRASIL, 2011, p. 167) ${ }^{6}$.

Nesse sentido, associando-se à Lei 13.415/2017, o documento se configura como um retrocesso, sobretudo em relação aos documentos elaborados na década de 1990, que propõem uma formação emancipatória para os alunos, como as Diretrizes Curriculares Nacionais (DCN), os Parâmetros Curriculares Nacionais (PCN) e o próprio Plano Nacional de Educação (PNE), visto que se caracteriza como uma proposta de redução ou "enxugamento" de conteúdos, priorizando aspectos relacionados ao saber fazer, isto é, à formação mais técnica "em detrimento de outros aspectos do conhecimento de base científico-tecnológica e sócio-histórica", conforme apontam Moura; Lima Filho (2017).

A contradição que pauta a (des) organização curricular é um ponto nevrálgico nas discussões dos documentos. Na versão atual, a própria Base insiste na necessidade de ensinar para a vida, de "assegurar aos estudantes uma formação que, em sintonia com seus percursos e histórias, faculte-lhes definir seus projetos de vida", (BRASIL, 2018, p.463), mas isso envolve inserir os alunos em práticas letradas, como a leitura diversificada, que permitam a contínua aprendizagem, pois elas são basilares para um melhor desempenho em outras áreas do conhecimento. E, concomitantemente, é importante lembrar que ler, escrever e calcular são práticas sociais que, embora perpassem diferentes componentes curriculares, não podem prescindir dos saberes construídos em outros campos do saber, como Filosofia, Sociologia, Artes, História, Geografia, Química, Física, Línguas estrangeiras, Educação Física etc.

Minimizar a importância dessas áreas no processo de formação dos alunos que estão no último segmento da educação básica fere princípios da proposta de formação humana integral tanto no Ensino Médio Integrado dito regular, quanto na modalidade de Educação de Jovens e Adultos. Uma reorganização curricular baseada em uma abordagem instrumentalista dos conteúdos não pode dar conta dessa proposta de facultar aos alunos a oportunidade de planificar "seus próprios projetos de vida", pois uma formação instrumental pode comprometer sua formação crítica, sua capacidade de agência cívica e seu protagonismo, quando thes subtrai o direito pleno à educação básica, oferecendo-lhes uma irreal oportunidade de escolha de itinerários formativos.

Um segundo conjunto de críticas, decorrente da suspeição de uma associação demais estreita entre ensino e avaliações de desempenho escolar, tanto nacionais como internacionais, refere-se a inconsistências no

\footnotetext{
${ }^{6}$ Documento citado na própria Base para o Ensino Médio (BRASIL, 2018, p. 463) 
modelo do ponto de vista estrutural, pois a organização curricular proposta tende a comprometer principalmente o princípio de formação integral, especialmente no que esse processo diz respeito à EPT. O conceito de educação integral refere-se, na BNCC, à construção intencional de processos educativos que promovam aprendizagens sintonizadas com necessidades, possibilidades e interesses dos estudantes e com os desafios da sociedade contemporânea. $\mathrm{O}$ documento assume explicitamente o compromisso com a formação integral ${ }^{7}$ dos alunos.

Contudo, ao enfatizar as ideias de competências e habilidades e de itinerários formativos, esse documento vai de encontro à noção de educação básica que garanta uma formação ampla aos alunos e traz em si marcas de um modelo de formação profissional que já se mostrou ineficaz desde o período da ditadura militar. Na divisão do currículo em itinerários formativos, cada um dos roteiros escolares determina conteúdos específicos das cinco áreas de ensino: Linguagens (e suas tecnologias), Matemática (e suas tecnologias), Ciências da Natureza, Ciências Humanas e Formação Técnica e Profissional o que abre a possibilidade de o aluno cursar apenas uma área, a de formação técnica e profissional, o que "constituiria uma interdição do seu direito a uma formação básica comum, com uma consequente intensificação de desigualdades educacionais" (SILVA; SCHEIBE, 2017, p. 26).

Mais problemático ainda é o modelo curricular que será ofertado, especialmente, aos alunos das escolas públicas, visto que, com a exceção dos colégios de aplicação, a escola pública brasileira não tem as devidas condições para oferecer diversos itinerários. Adquire-se assim, uma forte conotação instrumental de educação e perde-se um dos valores norteadores ${ }^{8}$ da BNCC, a promoção da equidade, que pressupõe reconhecer que as necessidades dos estudantes são diferentes, nas oportunidades de escolhas para a formação do aluno pela garantia de acesso ao mesmo conteúdo nas escolas de todo o país. A reversão da histórica situação de exclusão social continua comprometida neste cenário.

Embora a Reforma do Ensino Médio se faça necessária para corrigir alguns problemas, e nisso alguns estudiosos da EPT concordam, o formato escolhido tem como foco a estrutura curricular, em detrimento de outros aspectos da formação humana dos estudantes (HENRIQUE, 2016; MOURA; LIMA FILHO, 2017). Sendo assim, a reforma por si só não resolve os problemas desse segmento da educação básica. É importante considerar, dentre outras coisas, o fato de que a reforma negligencia problemas de infraestrutura básica, como os apontados por Moura; Lima Filho (2017, p. 120):

\footnotetext{
${ }^{7}$ Que não pode ser confundida, sob-hipótese alguma, com a ideia de escola em tempo integral.

${ }^{8}$ Os outros são igualdade e diversidade, (BRASIL, 2018, p. 17). 
ausência de instalações físicas adequadas, bibliotecas, laboratórios, espaços para a prática esportiva e de atividades artístico-culturais; inexistência de quadro de professores e demais trabalhadores da educação contratados por concurso público; planos de carreiras e de formação, salários dignos e condições de trabalho adequadas. Essas questões não são objeto da reforma. Logo, não se discutem as precárias condições de funcionamento das escolas e a absoluta necessidade de sua superação, indispensáveis à universalização da educação pública com qualidade socialmente referenciada.

Um fator contribuinte à atual (e futura) ausência de equidade do sistema educacional brasileiro, talvez mais importante no contexto da EPT ${ }^{9}$, que também abrange subsistemas educacionais longamente negligenciados, é a limitação imposta à formação humana integral, que necessariamente implica integrar as dimensões da ciência, da cultura e da tecnologia à do trabalho, visando à formação omnilateral ${ }^{10}$ do sujeito, com o objetivo de superar a dicotomia existente entre trabalho manual e trabalho intelectual por meio de um modelo de formação integral

na e para a vida, para a atuação política e social, para a produção de conhecimentos e para a produção de sua subsistência e dos demais sujeitos, ou seja, para o trabalho, o que permite ao indivíduo participar ativamente como cidadão e como profissional, compreendendo as relações que subjazem aos fenômenos (HENRIQUE, 2016, p. 3).

A BNCC propõe assumir uma visão plural, singular e integral da criança, do adolescente, do jovem e do adulto - considerando-os como

\footnotetext{
${ }^{9}$ Nesse cenário, há inclusive quem desconsidere que a EPT esteja situada no âmbito do ensino médio, mas, efetivamente, na Rede Federal de Educação Profissional Científica e Tecnológica, ela foi instituída pela Lei 11.892, de 29/12/2008, existe oferta sistematizada de cursos técnicos integrados ao ensino médio, também na modalidade de EJA, como o PROEJA, pensado para ofertar formação profissional, mas com a elevação do nível de escolaridade do aluno, o que normalmente não se observa nos cursos de EJA, os quais geralmente se desenvolvem em nível de alfabetização, assumindo um formato de educação compensatória.

${ }^{10}$ A noção de trabalho como princípio educativo e a formação omnilateral partem da Teoria Marxista, na qual a atividade laboral deve ser a base da humanização e da emancipação humana. Contudo, no sistema capitalista pode se tornar um elemento da degradação humana, quando torna o homem um ser alienado e um mero executor dessa atividade, destacando, assim, o caráter histórico negativo do trabalho nesse modo de produção (MARX, 2004). Na perspectiva marxista, assumir o trabalho como princípio educativo requer uma compreensão ampliada desta categoria, indo além do sentido histórico de trabalho alienado que assume sob o modo de produção capitalista. É preciso compreender a dimensão contraditória que o trabalho assume nesse contexto, pois ele tanto cria e humaniza, quanto aliena, degrada e submete o homem.
} 
sujeitos de aprendizagem - e promover uma educação voltada ao seu acolhimento, reconhecimento e desenvolvimento pleno, nas suas singularidades e diversidades. Todavia, deixa de discutir a situação das modalidades de ensino voltadas à formação do trabalhador na educação básica como a EPT, a EJA e a EAD (Educação a Distância). A promoção de uma educação comprometida com a singularidade e para a diversidade, que desconsidera as diferenças entre as modalidades de ensino se torna um problema por instituir tratamento desigual para diferentes grupos sociais que frequentam a escola: são tratados como iguais sendo diferentes ou são tratados de modos diferentes no que têm de iguais.

Sobre a problemática da oferta do PROEJA, que tende a ser cada vez mais resumida em alguns Institutos Federais, há descontinuidade na oferta de vagas, o que se configura, na visão de Santos Marques; Kleiman (2017), como uma ação contrária ao alcance dos objetivos traçados para o programa e para o próprio Plano Nacional de Educação. Evidentemente, não advogamos a instituição de ensino em tempo integral para a EJA/PROEJA, considerando a realidade de seus alunos e a necessidade de muitos deles estarem no mercado de trabalho enquanto estudam, mas não podemos naturalizar o fato de nada ter sido pensado em termos da oferta para os trabalhadores que estão ou estiveram excluídos da sala de aula pelas razões já por demais conhecidas. Por isso, defendemos um modelo formativo para a EPT, cujas bases estejam assentadas na concepção de formação humana integral e fazemos a crítica propositiva aos documentos ora em análise.

A ausência de discussão sobre o futuro de políticas públicas, como o PROEJA, em explícito esquecimento nas discussões sobre a Reforma do Ensino Médio, preocupa os estudiosos da área porque expõe a incompletude dessas novas diretrizes, mostrando traços do tratamento diferenciado e da exclusão a que estão expostos historicamente os alunos da EJA e do PROEJA no cenário político educacional brasileiro.

\section{LETRAMENTOS E TECNOLOGIAS DIGITAIS NA EDUCAÇÃO PROFISSIONAL E TECNOLÓGICA}

...eu já usava o computador aprendi no curso do telecentro, já conversava com os amigos até os de longe na internet. Tenho só que levar mais a sério aquilo de escrever com atenção e deixar pra falar normal em casa, na rua.

Na sociedade atual, a vida está profundamente marcada por mudanças decorrentes dos avanços tecnológicos, que impactam diversos aspectos das relações sociais. As tecnologias se manifestam no modo como nos 
comunicamos no trabalho, na escola, no grupo de amigos, na comunidade. Em razão disso, podemos afirmar que mudaram as nossas atividades cotidianas; conforme Barton; Lee (2015, p. 12), "é difícil encontrar uma área da vida que não tenha mudado. Pouco a pouco, as pessoas veem como absolutamente normal a transformação digital das atividades cotidianas".

$\mathrm{Na}$ contemporaneidade, a vida nas metrópoles ou nos locais mais afastados delas não pode prescindir do uso de ferramentas digitais que facilitem a interação e a conectividade com o mundo. Atualmente, quando a vida exige rapidez e agilidade em tudo que se faz, é mais prático e, certamente, mais eficaz usar um smartphone para enviar uma mensagem online no WhatsApp, do que postar uma carta pessoal em uma Agência de Correios. Do mesmo modo, é mais prático agendar uma consulta no site de uma clínica, do que ir à clínica ou telefonar para agendar, ou comprar antecipadamente ingressos no site de um cinema ou teatro do que enfrentar uma fila no momento do filme ou de um show ou espetáculo.

No atual contexto, podemos falar com alguém do outro lado do mundo, ouvir e ver a pessoa em tempo real e isso se tornou indispensável para a vida em sociedade. $O$ fato é que, se a vida contemporânea tem mudado velozmente, essas mudanças são determinantes para os processos de comunicação e se refletem nas práticas de leitura e escrita realizadas nas diferentes esferas da sociedade, em função do papel central que a linguagem online ${ }^{11}$ assume nesse processo de mudança.

Compreendida como espaço de informação, comunicação, conhecimento, trabalho e entretenimento, a educação do cidadão da cibercultura não pode ser dissociada do contexto das tecnologias digitais. $\mathrm{O}$ mundo do trabalho, por exemplo, assume um novo formato produtivo e se estrutura a partir de novas ferramentas e tecnologias. Como o documento da BNCC especifica, a informação e a comunicação digital precisam fazer parte do processo educacional. Na era digital, os alunos precisam se apropriar das ferramentas tecnológicas tanto para trabalhar quanto para viver.

Não restam dúvidas de que a informação, quando capitalizada como cultura pela escola, pode promover a aprendizagem do estudante e do cidadão em seus diferentes papéis sociais, mas para isso a escola da atualidade precisa ter clareza do que pode ser feito com as tecnologias digitais para favorecer a formação crítica do aluno. Especialmente no caso de estudantes da EJA, o processo de letramento digital precisa se desenvolver com cuidado para que ele não se torne mais uma das razões da evasão de muitos jovens e adultos, consequência do hiato que geralmente as práticas escolares ocasionam na vida cotidiana deles.

Espera-se, das políticas públicas nacionais, a produção de documentos que levem em conta as circunstâncias específicas dos

\footnotetext{
${ }^{11}$ Como propõem Barton; Lee (2015, p. 19), "Online é usado como um termo conveniente e uma abreviação para todas as formas de comunicação realizadas em dispositivos de rede".
} 
segmentos educacionais cujas ações se pretende afetar. No contexto da EPT, onde historicamente se conflitam o humanismo e a técnica, os processos formativos ainda estão muito comprometidos com questões técnicas e tecnológicas e não com a formação humana dos estudantes. Sendo assim, trabalhar na perspectiva de humanizar as informações e o conhecimento torna-se importante. A esse respeito, são relevantes as considerações de Freire (1979, p. 62): "Numa era cada vez mais tecnológica como a nossa, será menos instrumental uma educação que despreze a preparação técnica do homem, como a que, dominada pela ansiedade de especialização, se esqueça de sua humanização".

$\mathrm{Na}$ BNCC para o Ensino Médio, a ênfase em tecnologias digitais sem um modelo educativo inovador que incorpore estratégias de formação humana em uma perspectiva crítica, aliada ao caráter prescritivo de documentos dessa espécie, é preocupante: o despertar da consciência crítica do estudante em relação aos jogos de poder e de interesses políticos e econômicos não se origina, via de regra, na compreensão do funcionamento e os recursos oferecidos pela tecnologia digital, seja para o tratamento das linguagens - "mixagem, sampleamento, edição, tratamento de imagens etc." (BRASIL, 2018, p. 483), seja para as "possibilidades de remidiação ${ }^{12}$ abertas pelos fenômenos multimídia e transmídia, característicos da cultura da convergência" (BRASIL, 2018, p. 483).

Tampouco um professor sobrecarregado com sua rotina diária de aulas conseguirá ensinar aos seus alunos a atuar eficientemente nos campos das práticas de estudo e de pesquisa; pelo contrário, provavelmente, seguirá as sugestões do documento nacional e acabará enfocando detalhes secundários e totalmente prescindíveis, como a elaboração de slides que utilizem "tipos e tamanhos de fontes que permitam boa visualização", que organizem o conteúdo "em itens" e que insiram "de forma adequada imagens, gráficos, tabelas, formas e elementos gráficos dimensionando a quantidade de texto e imagem por slide" e culminando no uso "de forma harmônica, recursos (efeitos de transição, slides mestres, layouts personalizados, gravação de áudios em slides etc.)" (BRASIL, 2018, p. 509).

O fato de o estudante ter a possibilidade de agir à distância, desvinculado de seu lugar de origem, pode auxiliar na construção de nova identidade emancipada ou pode isentá-lo de responsabilidade social, tornando-o descompromissado de qualquer problema local. As recomendações da BNCC, ao enfatizar a formação ética do aluno de Ensino Médio, parecem levar em conta essa dupla possibilidade, quando apontam,

\footnotetext{
${ }^{12} \mathrm{Na}$ esfera jornalística, "midiação" é um termo cunhado por John B. Thompson, estudioso das relações entre cultura e ideologia e autor da obra "Ideologia e Cultura Moderna", publicada em 1995. Nessa obra, ele sistematiza uma Teoria social da comunicação de massa para indicar o processo de mediação da instituição mídia. Não conseguimos achar 'remidiação'. Esperamos que o professor usuário do documento seja mais bem sucedido na sua busca.
} 
em relação ao desenvolvimento de competências nas práticas digitais, que "os jovens precisam ter uma visão crítica, ética e estética, e não somente técnica das TDIC e de seus usos, para selecionar, filtrar, compreender e produzir criticamente sentidos em quaisquer campos da vida social" (BRASIL, 2018, p. 489). Mas o discurso teórico se contrapõe a competências e habilidades sugeridas.

Considerando as reais condições das escolas públicas do país, elas não estão devidamente estruturadas para implementar as mudanças necessárias para o acesso do aluno ao mundo digital, em função do sucateamento em que se encontram. Nessas condições, dificilmente, irão aprender a fazer um slide harmônico, legível e esteticamente agradável. Vale a pena o esforço despendido por professor e alunos? O tempo gasto com isso não seria mais bem utilizado aprendendo como se fazer ouvir por grupos sociais poderosos, como falar e escrever para promover e participar de mudanças, como aprender a ler e a escrever para lutar por seus direitos?

Todas essas possibilidades são impensáveis para o aluno da EPT hoje, quando é mais acentuada a diferença entre aqueles que transitam livremente pelo ciberespaço, "os que estão no alto" (BAUMAN, 1998, p. 17) e assim são ouvidos globalmente, e aqueles trabalhadores tradicionais que continuam restritos ao seu espaço-tempo local e a suas redes sociais imediatas (KLEIMAN; VIEIRA, 2006). São estes últimos, sujeitos estigmatizados, pertencentes a grupos não politizados, os excluídos digitais que frequentam, majoritariamente ${ }^{13}$, os programas de EPT/PROEJA no país.

Retomando a BNCC, o documento destaca, entre as competências gerais da educação básica, utilizar tecnologias digitais de comunicação e informação de forma crítica, significativa, reflexiva e ética nas diversas práticas do cotidiano (incluindo as escolares) ao se comunicar, acessar e disseminar informações, produzir conhecimentos e resolver problemas (BRASIL, 2018, p. 9). Atingir esse objetivo dependerá, necessariamente, de uma reflexão sobre as tecnologias em que se interrogue o seu papel na formação geral dos alunos. Mais relevante do que determinar quais são essas tecnologias, é preciso saber como se dá o acesso a elas na sociedade letrada; se e como ocorre a democratização dos recursos tecnológicos na sociedade e a quem serve a adesão ingênua do trabalhador em formação à tecnologia.

A reflexão alicerçada na realidade nacional, esperada num documento basilar, é praticamente inexistente na BNCC, sendo substituída por tecnicismos que sequer levam em conta, na EPT, a formação do professor e as necessidades do aluno. Não podemos esquecer, como o documento parece fazê-lo, que, numa sociedade caracterizada pela modernidade tecnológica, mas também com um grande contingente de população com

\footnotetext{
${ }^{13}$ As exceções se encontram em geral nos colégios técnicos sob a responsabilidade das universidades públicas brasileiras. 
pouca escolaridade, como a brasileira, que, a questão do letramento digital crítico é atravessada (e atropelada) pela questão do letramento - usos da língua escrita - do estudante. Ao contrário do que se afirma no documento, que "as habilidades requeridas por processos de recuperação de informação (identificação, reconhecimento, organização) e por processos de compreensão (comparação, distinção, estabelecimento de relações e inferência) já foram desenvolvidas no Ensino Fundamental" (BRASIL, 2018, p. 491), a realidade educacional nacional permite prever, com alto grau de segurança, que, para muitos alunos, elas não foram desenvolvidas.

\section{IMPACTO DAS TECNOLOGIAS DIGITAIS NA EPT INTEGRADA À EJA NAS PALAVRAS DE UM ALUNO TRABALHADOR}

Foi surpresa chegar no estágio achando que já sabia usar o computador, porque a gente já tinha aprendido até a usar o blog, o twitter, mandar mensagem e aí descobrir que sabe pouco.

A epígrafe, assim como as anteriores, nos mostra as consequências da grande distância entre declarações sobre objetivos, metas e intenções no Ensino Médio e as habilidades propostas para, de fato, inserir os jovens na cultura digital, nos multiletramentos e (segundo denominação do documento) nos novos letramentos. Diferente seria o resultado se habilidades fossem substituídas por práticas sociais, seja qual for a esfera de ação envolvida.

A formação do sujeito trabalhador deve ir além de uma formação meramente técnica, não se limitando a formas de conhecimento empírico, e assumir a concepção de um sujeito situado em um dado contexto social e histórico, em permanente processo de formação ao longo da vida, capaz de produzir, em uma perspectiva crítica, conhecimento científico, tecnológico e cultural (IFRN, 2012). Em outras palavras, uma concepção que incorpora o impacto identitário das novas tecnologias nas áreas da vida pública e privada em que atua o sujeito ${ }^{14}$.

\footnotetext{
${ }^{14} \mathrm{O}$ impacto identitário da cultura digital é um importante elemento a ser levado em conta na formulação de projetos educacionais, segundo Kleiman; Vieira (2006, p. 129). Para as autoras, "Em face da mobilidade, incorporeidade, anonimato e desarraigamento do sujeito virtual, conformado pelas recentes TIC e dos efeitos desses aspectos identitários em práticas discursivas potencialmente descompromissadas, desumanizadas, homogeneizantes e acríticas, é inegável a necessidade de projetos de inclusão digital que contrapunham a essas características a liberdade de ousar e de inovar, o risco de se aventurar por novos territórios, o distanciamento crítico".
} 
O depoimento de Paulo, aluno do Curso de Eletrotécnica do PROEJA ${ }^{15}$, feito no decorrer de sua participação em um projeto de letramento (KLEIMAN, 2000; OLIVEIRA; TINOCO; SANTOS, 2011), visibiliza o caráter complexo dos processos de letramento (digital, profissional e escolar) que 0 envolveram na sua trajetória de escolarização:

Foi surpresa chegar no estágio achando que já sabia usar o computador, porque a gente já tinha aprendido até a usar o blog, o twitter mandar mensagem e aí descobrir que sabe pouco. O pior é que o serviço que faço no estágio nem precisa tanto de computador. Para que saber informática? a empresa pega a gente e manda carregar peso para o almoxarifado. Para que se preparar pra usar o computador e depois quererem você pra descarregar caminhão de mercadorias? Nem dá para entender por que tenho que fazer esse tipo de trabalho se no estágio eu teria mesmo era que saber consertar computador, não? Eu sei usar. Todo dia uso o computador para bater papo com os amigos etc. etc. Já sei montar e desmontar o computador, porque isso é a parte técnica do curso, mas no trabalho o que escrevo está errado. Só querem que registre a quantidade dos produtos (peças) que entra e sai na ficha (Planilhas, não é?). Sei que preciso aprender e posso, porque eu sou do IFRN e o Proeja é a oportunidade de mudar minha vida e melhorar nisso também, para não perder o trabalho. Esse projeto tem me ajudado nisso também, entende? [...] Acho importante aprender a escrever o relatório de estágio, o currículo, fazer e-mail etc. [...] Também é importante pensar sobre o que fazemos no curso. No projeto, discute muita coisa sobre o que fazemos na sala, o que achamos do estudo e o que queremos aprender. Assim, ficamos mais conscientes, não é? Por um lado isso é bom, mas por outro a gente não se conforma com certas coisas [...] Tem colegas mais velhos com mais dificuldade chegando a pensar em abandonar o curso por causa do uso do computador [...] eu já usava o computador aprendi no curso do telecentro, já conversava com os amigos e até os de longe na internet. Tenho só que levar mais a sério

\footnotetext{
${ }^{15}$ A vida escolar do aluno foi marcada por uma relação complicada de acesso e permanência na escola pela necessidade de trabalhar para garantir sua sobrevivência. No que diz respeito ao letramento digital, não dispunha na ocasião da pesquisa de modernas tecnologias na sua residência (tablet, computador e celular de última geração nem de acesso fácil à internet), mas utilizava costumeiramente as redes sociais em casa, no estágio e em lan house, quando tinha uma necessidade maior e mais imediata de se comunicar com alguém. Mesmo assim, ele compreendia que tinha um bom domínio das tecnologias como afirma no seu depoimento. A nosso ver, quando se tratar do uso das tecnologias para o mundo do trabalho, a escola precisa ter clareza do que ensinar sobre seus usos. O depoimento do aluno sugere que é preciso investir mais no letramento digital deles, considerando também suas necessidades para o mundo do trabalho.
} 
aquilo de escrever com atenção e deixar para falar normal em casa, na rua.

Conforme seu depoimento, o aluno tem domínio de tecnologias digitais -"Eu sei usar [...]". Mas o fragmento traz à tona aspectos preocupantes do processo de letramento desse aluno, pois seus saberes não são legitimados no local de trabalho. Embora ele afirme que sabe usar o computador e tenha noção de escrita como tecnologia, já que ele afirma usar a escrita para realizar coisas e atender a necessidades na vida cotidiana, sua escrita não é legitimada no contexto de estágio.

Há aí um conflito que desafia a escola a dar respostas ao aluno. Se por um lado, ela precisa pensar o que, para que, por que e como ensinar o padrão formal escrito, ensinando a escrever situadamente, por outro, precisa também trabalhar contra a discriminação pela língua, tornando-a instrumento de acesso e poder e não de exclusão social, pensando possibilidades de ensinar e aprender a escrever. De acordo com Kleiman (2012, p. 35),

A tarefa de aprender uma variante diferente da língua é enorme. Também é enorme a tarefa de reverter a situação dos dominados na situação de conflito diglóssico. A escola tem o dever de mudar a percepção da sociedade sobre o que está envolvido na aprendizagem de um segundo dialeto.

Também é papel da escola trabalhar para legitimar a escrita dos alunos de classes sociais marginalizadas, como a dos que geralmente frequentam as salas de aula do PROEJA. Isso se faz quando se oferece a eles uma educação linguística de qualidade. Se o domínio da norma-padrão por si só não lhes garante acesso e inclusão social, sem esse domínio esses alunos não serão fortalecidos, ganhando voz. Não basta focar no ensino da norma, pois ganhar voz significa aprender a ler e a escrever e a usar as práticas letradas nas diversas situações sociais. Para ganhar voz, os alunos precisam ir além da língua deles (SANTOS, 2012), dominando outras variantes linguísticas, segundo os gêneros mobilizados para participar das práticas de uso da linguagem na escola, igreja, trabalho, etc., e nas redes sociais nelas estabelecidas. Uma tarefa nem trivial, nem fácil. Do jeito que o aluno sabe falar, escrever e se fazer entender por seus pares nas redes sociais, ele tem o direito de aprender a usar a escrita no trabalho, na escola, nos ambientes de lazer etc., ganhando autonomia ao ir-se inserindo, por meio de práticas cada vez mais diversificadas, no tecido social. As mudanças na vida do aluno se dão também pelos usos da linguagem, pois ganhar voz significa, entre outros aspectos, se tornar cidadão letrado. Nas palavras de Paulo Freire, 
A profundidade da significação do ser cidadão passa pela participação popular, pela "voz". Quando eu digo voz é mais do que isso que eu estou fazendo aqui. Não é abrir a boca e falar, recitar. A voz é um direito de perguntar, criticar, de sugerir. Ter voz é ser presença crítica na história. Ter voz é estar presente, não ser presente. Nas experiências autoritárias, tremendamente autoritárias, o povo não está presente. Ele é representado. Ele não representa (FREIRE, 2001, p. 130-131).

Quando o aluno considera a possibilidade de deixar de usar a sua própria língua no estágio, isto é, "deixar pra falar normal em casa, na rua", seu enunciado sugere a existência de uma consciência linguística crítica bastante aguçada, evidente no reconhecimento de que a legitimação de sua escrita depende da capacidade para falar e escrever seguindo parâmetros normativos.

Contudo, o enunciado revela também uma autoestima comprometida pelo tratamento preconceituoso recebido no estágio, quando é desviado da sua função, na qual trabalharia na montagem e desmontagem de computadores, consertando-os, e é colocado no "serviço pesado", descarregando o caminhão de mercadorias. Ao dizer que não adianta saber usar o computador, isto é, ser letrado digitalmente, para trabalhar nesse tipo de "serviço pesado", ele está relatando tanto a discriminação sofrida como seus direitos interditados. Na sociedade estratificada em que esse aluno se insere, o lugar dos que não dominam a escrita é o trabalho pesado, a exploração e a segregação. Tornando-se ciente de sua condição na sociedade letrada, ele adquire uma potencial consciência linguística, reconhecendo as relações de poder que atravessam os usos sociais da linguagem.

Á escola cabe, portanto, o papel de ampliar os múltiplos letramentos do aluno para torná-lo mais empoderado. Nas palavras de Giroux (1999, p. 21), empoderamento "é a capacidade de pensar e agir criticamente". Isso ocorre quando, por exemplo, valorizam-se procedimentos de escuta e instituem-se práticas e metodologias dialógicas, favorecendo a conscientização política dos alunos, seu potencial de resiliência e sua capacidade crítica ${ }^{16}$. A discussão acerca do impacto do domínio do padrão formal escrito na vida do trabalhador, nos mostra que a mudança de vida desse aluno não pode prescindir de um trabalho sistematizado com a linguagem no contexto de sala de aula, embora não se limite a isso.

Também observamos no depoimento do aluno que ele declara ter domínio de tecnologias, sabe usar o computador, mas, que no trabalho/estágio, sua atividade configura-se como algo meramente mecânico,

\footnotetext{
${ }^{16}$ De acordo com Kincheloe (1997, p. 186), "ser crítico é pressupor que os humanos são agentes ativos cuja autoanálise reflexiva e cujo conhecimento de mundo leva à ação".
} 
consistindo na reprodução de ações (registrar a quantidade, a saída e a entrada de peças). A fala sobre essa quebra de expectativas aponta que está equivocada a orientação de formação baseada em competências, pensada para atender aos interesses de mercado da sociedade neoliberal, visto que ela serve para explorar o trabalhador.

A educação não deve ser copartícipe dessa exploração. Considerando nossa realidade excludente, a noção de competências e habilidades na EPT precisa ser superada porque reduz a capacidade criativa e criadora do trabalho a um conjunto de tarefas (RAMOS, 2010). Na perspectiva instrumentalista, forma-se a classe trabalhadora para reproduzir o status quo, sem oportunizar a reflexão sobre sua própria condição. O desenvolvimento tecnológico, a ciência e a técnica, por mais avançados que estejam, não resolveram os problemas da classe trabalhadora, pois, muitas vezes, servem apenas aos interesses do capital.

Resumindo, diante da realidade complexa e desafiadora que é formar a classe trabalhadora deste país, para começar a atender às expectativas, necessidades e direitos dos alunos da EPT, é importante que observemos o seguinte conjunto de princípios: 1) um ensino em que a técnica e a tecnologia não se sobreponham à formação humana integral, trabalhando conteúdos socialmente relevantes em uma abordagem crítica e emancipatória, assumindo as tecnologias digitais como meios para estabelecer o diálogo entre os conhecimentos da formação geral e da formação técnica; 2) um ensino menos instrumental, que valorize a capacidade reflexiva do educando e o ajude a pensar de forma crítica, para não se submeter cegamente às formas de controle e servidão impostas nas relações de trabalho; 3) um ensino que, considerando as demandas do mundo do trabalho, leve em conta as necessidades de aprendizagem dos educandos, observando atentamente suas condições de trabalho e seus direitos como trabalhador; 4) um ensino que valorize as experiências dos estudantes e sua vinculação aos temas da atualidade, pensando na sua capacidade de intervir propositivamente em sua realidade como um agente de mudanças; 5) um ensino em que os letramentos sejam entendidos como instrumentos de acesso e poder; 6) um ensino que valorize o caráter interdisciplinar dado à abordagem dos conteúdos como condição de superação da fragmentação, comumente associada à produção do conhecimento no contexto escolar, possibilitando maiores chances de articulação entre a vida dentro e fora da escola.

\section{CONSIDERAÇÕES FINAIS}

Neste artigo, tivemos por objetivo discutir aspectos que envolvem o trabalho com as tecnologias digitais no processo educacional de alunos vinculados ao Ensino Médio Integrado no contexto específico do PROEJA, tecendo considerações sobre algumas ambiguidades e omissões observadas 
em documentos regulatórios do Ensino Médio que caracterizam o tratamento da Educação Técnica e Profissional nas diversas políticas públicas da federação.

Discutimos a EPT no cenário de implementação da Reforma do Ensino Médio e da Base Nacional Comum Curricular para o Ensino Médio (BNCC), focalizando problemas e limitações dessas políticas públicas em relação aos Cursos Técnicos, tendo como foco de interesse o PROEJA, analisando o tratamento diferenciado dado à EPT e especialmente, a esse programa, desconsiderando-se a realidade complexa que envolve essas modalidades de ensino. Para ampliar essa discussão, tratamos também das recomendações da BNCC sobre tecnologias digitais.

Posteriormente, tomando por base um depoimento de um aluno do PROEJA, vítima de discriminação pela falta de domínio do padrão monitorado escrito, exigido no mundo do trabalho, o qual se orienta pela norma-padrão e pelas variantes de maior prestígio social, ilustramos aspectos práticos do processo de letramento em que estão implicados usos das tecnologias digitais na formação técnica para o trabalho, examinando as reais possibilidades de utilização de tecnologias de forma crítica, significativa, reflexiva e ética no segmento educacional em foco.

Além disso, a título de contribuições à crítica que fizemos ao cenário atual em que se situa a Educação Profissional nas discussões acerca das políticas públicas educacionais e da implementação de novos documentos reguladores do Ensino Médio, propomos alguns princípios que, uma vez observados no contexto da EPT, poderiam nortear o trabalho com as práticas de letramento desenvolvidas na sala de aula, para começar a atender às expectativas, necessidades de participação social e política dos estudantes.

Por fim, nestas considerações finais, refletimos que, enquanto os trabalhadores em formação, a exemplo de Paulo, cujo desabafo foi aqui analisado, ou outros possíveis alunos egressos da EPT continuarem chegando ao mundo do trabalho sem que a escola tenha dado respostas mais concretas às suas demandas de letramentos, esta continuará sendo reprodutora de desigualdades sociais, pois não garante aos educandos o direito aos letramentos como condição de acesso e permanência no mundo do trabalho e de inclusão social.

Acreditamos que é chegada a hora de dividir a responsabilidade de formação leitora e escritora dos alunos entre todas as áreas do conhecimento. A assunção compartilhada dessa responsabilidade pode favorecer o desenvolvimento de metodologias dialógicas e a implementação de uma cultura interdisciplinar de produção do conhecimento no contexto escolar, dando um tratamento crítico aos conteúdos. Isso pode inserir o processo de letramento dos educandos em um viés crítico, contribuindo para que alcancem a cidadania plena, visto que educação de qualidade é um 
direito que não pode ser subtraído dos alunos que se encontram na educação básica.

\section{REFERÊNCIAS}

BARTON, D.; LEE, C. Linguagem online: textos e práticas digitais. São Paulo: Parábola Editorial, 2015.

BAUMAN, Z. Globalização: as consequências humanas. Rio de Janeiro: Jorge Zahar Editor, 1998.

BRASIL. LDB : Lei de diretrizes e bases da educação nacional : Lei no 9.394, de 20 de dezembro de 1996 - 11. ed. - Brasília : Câmara dos Deputados, Edições Câmara, 1996.

Conselho Nacional de Educação. Parecer CNE/CEB n. 5/2011.

Diretrizes Curriculares Nacionais para o Ensino Médio. Diário Oficial da União, Poder Executivo, Brasília, DF, 24 jan. 2011. Seção 1, p. 10.

Ministério da Educação. Secretaria da Educação Básica. Base

Nacional Comum Curricular - Ensino Médio. Brasília-DF; MEC; CONSED; UNDIME, 2018. Disponível em: http://basenacionalcomum.mec.gov.br/documento/BNCC.pdf. Acesso em: 08/06/2018.

ADORNO, T. W. Indústria cultural e sociedade. São Paulo: Paz e Terra, 2002.

FREIRE, P. Educação e mudança. Rio de Janeiro: Paz e Terra, 1979.

Pedagogia da autonomia: saberes necessários à prática educativa. São Paulo: Paz e Terra, 1996.

Pedagogia dos sonhos possíveis. São Paulo: Editora UNESP, 2001.

GIROUX, H. A. Cruzando as fronteiras do discurso educacional: novas políticas em educação. Porto Alegre: Artes Médicas Sul, 1999.

HENRIQUE, A. L. S. Novos Rumos para os Cursos de Licenciatura. Palestra proferida na VI Semana de Química, no IFPB, João Pessoa/PB, em 18/10/2016.

IFRN. Instituto Federal de Educação, Ciência e Tecnologia do Rio Grande do Norte. Projeto político-pedagógico do IFRN: uma construção coletiva documento-base. Natal: IFRN Ed., 2012.

KINCHELOE, J. L. A formação do professor como compromisso político: mapeando o pós-moderno. Porto Alegre: Artes Médicas, 1997.

KLEIMAN, A. B. O processo de aculturação pela escrita: ensino de forma ou aprendizagem da função? In: KLEIMAN, A. B.; SIGNORINI, I. O ensino e a formação do professor: alfabetização de jovens e adultos. Porto Alegre: Artes Médicas do Sul, 2000. 
EJA e o ensino da língua materna: relevância dos projetos de letramento. Rev. EJA EM DEBATE. Florianópolis, vol I, p. 23-38, nov. 2012.

KLEIMAN, A. B.; VIEIRA, J. A. O impacto identitário das novas tecnologias da informação e comunicação, In: MAGALHÃES, I., CORACINI, M. J. \& GRIGOLETTO, M. (Orgs.). Práticas identitárias: língua e discurso. São Paulo: Editora Claraluz, 2006, p.119-132.

MARX, K. Salário, preço e lucro. In Antunes, Ricardo (Org.) A dialética do trabalho: escritos de Marx e Engels. SP: Expressão Popular, 2004.

MOURA. D. H.; D. L. LIMA FILHO. A reforma do ensino médio: Regressão de direitos sociais. Revista Retratos da Escola, Brasília, v. 11, n. 20, p. 109129, jan./jun. 2017. Disponível em: http://www.esforce.org.br>. Acesso em: 09 de jun de 2018.

OLIVEIRA, M. S.; TINOCO, G. M. A. M.; SANTOS, I. B. A. Projetos de letramento e formação de professores de língua materna. Natal: EDUFRN, 2011.

RAMOS, M. N. Implicações políticas e pedagógicas da EJA integrada à educação profissional. Educação \& realidade. Porto Alegre, v. 35, n. 1, p. 65-85, jan./abr. 2010. Disponível em: http://seer.ufrgs.br/index.php/educacaoerealidade/issue/viewlssue/935/392. Acesso em 09/06/2018.

SANTOS, I. B. A. Projetos de letramento na educação de jovens e adultos: o ensino da escrita em uma perspectiva emancipatória. Natal, 2012. Tese (Doutorado em Estudos da Linguagem/Linguística Aplicada) - Universidade Federal do Rio Grande do Norte - UFRN.

SANTOS MARQUES, I. B. A; KLEIMAN, A. B. Educação profissional para além da formação técnica e tecnológica. Revista EJA em debate, v. 6, n. 9, 2017. https://periodicos.ifsc.edu.br/index.php/EJA/article/view/2294/ART. Acesso em 09/06/2018.

SILVA, M. R.; SCHEIBE, L. Reforma do ensino médio: pragmatismo e lógica mercantil. Revista Retratos da Escola, Brasília, v. 1, n. 20, jan./jun. p. 19-31, 2017. Disponível em: http://www.esforce.org.br. Acesso em 09/06/2018.

THOMPSON, J. B. Ideologia e cultura moderna. Petrópolis, RJ: Vozes, 1995. 